\title{
Democratizando a ciência no cenário internacional: um debate sobre conceito de comunidades epistêmicas e sua perspectiva da ciência na política internacional
}

Democratizing science on the international scene: a debate on the concept of epistemic communities and its perspective of science in international politics

Nicole Aguilar Gayard *

\section{RESUMO}

O artigo retoma os debates e premissas sobre a democratização da governança em ciência e tecnologia, e os compara com a perspectiva da ciência predominante no conceito de comunidades epistêmicas no campo das relações internacionais. Ressalta os diferentes entendimentos sobre o binômio "ciência e tecnologia" nas abordagens debatidas. A revisão e comparação entre perspectivas da ciência aportadas pelos estudos sociais da ciência e tecnologia e pelas relações internacionais busca contribuir com $\mathrm{O}$ debate da democratização e engajamento público em ciência e tecnologia para além de uma perspectiva nacional. Conclui-se pela necessidade de integrar perspectivas e debates contemporâneos sobre uma produção de conhecimento heterogênea e múltipla na análise do conhecimento nas relações internacionais.

Palavras-chave: Governança em C\&T; Democratização; Comunidades Epistêmicas (Relações Internacionais).

\begin{abstract}
This article explores the debates around calls and experiments of democratization in science and technology governance, and compares them with the perspective of science embedded in the concept of epistemic communities, as employed by International Relations theories. It emphasizes the different understandings about "Science and Technology" in each of these approaches. The review and comparison between perspectives of science provided by the Social Studies of Science and Technology and International Relations seeks to contribute to the debate of democratization and public engagement in science and technology beyond a national perspective. The article concludes by pointing to the necessity of recognizing contemporary perspectives of knowledge, as a heterogeneous field of action composed by multiple actors and networks, for an improved analysis of the role of knowledge in international politics.
\end{abstract}

Keywords: Governance in S\&T; Democratization; Epistemic Communities (International Relations).

\footnotetext{
* Bacharel em Relações Internacionais pela Universidade de São Paulo (USP). Mestre e doutora em Política Científica e Tecnológica pela Universidade Estadual de Campinas (Unicamp). Professora substituta do curso de Relações Internacionais da Universidade Federal de Uberlândia. Instituto de Economia UFU - Av. João Naves de Ávila, 2121 - Bloco J, Campus Santa Mônica - Cep: 38408-100 Uberlândia-MG. Telefone: (34) 3239-4157. E-mail: nicolegayard@gmail.com.
} 


\section{INTRODUÇÃO}

No âmbito de inumeráveis esforços de teorização do papel da ciência e tecnologia nas sociedades e processos políticos contemporâneos em diversos campos de pensamento, o conceito de comunidades epistêmicas aparece como a forma mais difundida nas análises de relações internacionais, visando explicitar a importância do conhecimento e de processos de aprendizagem na formulação de políticas internacionais. No contexto em que emergiram enquanto conceito teórico, as comunidades epistêmicas propuseram justamente reconhecer 0 aspecto fundamental do conhecimento de base científica e tecnológica na compreensão da realidade política com que se defrontam diferentes países em seus processos de definição e coordenação políticas, em que pese os problemas transfronteiriços com que se deparam em uma variedade de áreas temáticas. O conhecimento, de acordo com essa abordagem, tem a capacidade de afetar e contribuir com a política internacional cooperativa ao longo de todo o processo de negociação: desde a identificação e concepção do problema - em termos respaldados pelo conhecimento e expertise disponíveis - até a proposta de soluções compartilhadas, também ancoradas em um saber legítimo e compartilhado por especialistas.

Apesar do destaque adquirido na década de 1990, impulsionado pelo lançamento de uma edição especial dedicada ao conceito na revista International Organization em 1992, a abordagem das comunidades epistêmicas e as análises decorrentes do reconhecimento do papel da ciência na política internacional parecem ter perdido fôlego no campo das relações internacionais nas décadas que se seguiram. Esse declínio, no entanto, contrapõe-se a uma tendência de crescente reconhecimento do papel da ciência em demais áreas das ciências sociais. De particular interesse, situamse análises que avançam uma perspectiva construtivista da ciência e se voltam para compreender e investigar formas mais abertas e participativas de produção do conhecimento nas sociedades contemporâneas.

Com o intuito de dialogar com os avanços das perspectivas de ciência aberta e crescente participação, tanto nos espaços de produção do conhecimento quanto nas esferas decisórias, o presente artigo apresenta as limitações do conceito de comunidades epistêmicas em pensar uma perspectiva mais ampliada e participativa da produção do conhecimento, e chama a atenção para novas questões que se colocam na consideração de uma ciência ampliada no cenário internacional.

$\mathrm{O}$ artigo se divide em três seções. A primeira apresenta o conceito e as limitações das comunidades epistêmicas, da forma como proposta no campo das relações internacionais, para pensar temas de governança e o papel da ciência e tecnologia diante de uma perspectiva construtivista do conhecimento e de seus novos modos de produção, avançados pelo campo dos estudos sociais da ciência e tecnologia. A segunda seção apresenta os desenvolvimentos da ciência e participação pública. Discute os conceitos, formatos e premissas revelados pelas análises de experimentos de participação pública em ciência e tecnologia em diferentes contextos. A terceira seção cita exemplos de incorporação de propostas de maior participação pública na ciência em iniciativas internacionais, ao menos no que se refere aos discursos e documentos oficiais. 


\section{GOVERNANÇA DA C\&T NO CENÁRIO INTERNACIONAL: COMUNIDADES EPISTÊMICAS E CONHECIMENTO NAS RELAÇÕES INTERNACIONAIS}

As diferentes demandas por abertura e participação que se apresentaram ao campo científico desde a década de 1960 encontraram pouco espaço nas teorizações das relações internacionais. Por muito tempo, prevaleceu no campo uma abordagem estadocêntrica, e as considerações do papel da ciência foram principalmente incorporadas por meio de abordagens funcionalistas (MITRANYI, 1943), neofuncionalistas e de economia política internacional (STRANGE, 2015). O conceito de comunidades epistêmicas ganhou destaque, principalmente a partir de 1992, como instrumento de análise acerca do papel do conhecimento e das redes de aconselhamento científico ao processo político.

A publicação da edição especial de International Organization, editada por Peter Haas, apresentou as bases teóricas e conceituais dessas comunidades, compostas por "profissionais com reconhecida expertise em determinado domínio de conhecimento, e com autoridade para tratar de elementos que demandem conhecimento relevante na formulação de políticas em determinada área" (HAAS, 1992, p. 3). O autor explica, em nota de rodapé, que as comunidades epistêmicas não precisam ser compostas exclusivamente por cientistas ou profissionais que compartilham as metodologias da ciência. $\mathrm{O}$ que mantêm unidos os membros de uma comunidade epistêmica é sua crença compartilhada ou fé na veracidade e aplicabilidade de formas particulares de conhecimento ou fatos específicos. Assemelha-se, assim, à ideia de "coletivo de pensamento", elaborada no campo da sociologia por Ludwig Fleck, consistindo em um grupo sociológico com estilo de pensamento comum. Os profissionais que compõem tais comunidades podem advir de campos distintos, mas possuem um conjunto de opiniões normativas compartilhadas e, portanto, uma lógica comum para a ação social. Essas comunidades teriam um papel fundamental para a conformação de regimes internacionais ${ }^{1}$ em questões técnicas, como seria o caso dos problemas ambientais internacionais e de temas de segurança, comércio e economia política internacional.

A teoria das comunidades epistêmicas apresenta uma abordagem de acordos de cooperação internacionais baseada no aprendizado que estes promovem entre os países. Reconhece a importância do conhecimento no trato de questões internacionais e insere a difusão cientifica como agente facilitador da cooperação. $O$ papel da ciência se destaca na conformação de políticas e entendimentos comuns no cenário internacional, na medida em que muitas das normas acordadas entre países são definidas com base no conhecimento disponível. São quatro os elementos de conhecimento contidos nas comunidades epistêmicas:

a) Representam um conjunto compartilhado de crenças normativas que provê um fundamento para a ação social.

b) Compartilham crenças causais, que derivam de sua análise de práticas levando ou contribuindo a um conjunto central de problemas em seu domínio, e que servem como base para elucidar múltiplas ligações entre ações políticas possíveis e resultados desejados.

\footnotetext{
${ }^{1}$ Regimes internacionais consistem em "um conjunto de normas, princípios, regras e procedimentos de tomada de decisão, implícitos ou explícitos, em torno dos quais as expectativas de atores internacionais convergem" (KRASNER, 1983).
} 
c) Possuem noções compartilhadas de validade, ou seja, critérios internamente definidos, intersubjetivos, para a validação de conhecimento em seu domínio de expertise.

d) Propõem um direcionamento político comum, ou seja, um conjunto de práticas associadas a um conjunto de problemas, para os quais sua competência profissional está direcionada.

Algumas vezes tratado como parte de uma vertente neofuncionalista (HAAS, 2008; LITFIN, 1994), manifestando confiança na racionalidade técnica para enfrentar questões sociais; em outros trabalhos, o conceito é apontado como construtivista (HAAS, 2001; HAAS, P.M.; HAAS, E. B., 2002). É importante notar, entretanto, que apesar de reconhecer a possibilidade de que o conhecimento seja socialmente construído, as comunidades epistêmicas, uma vez formadas, são tomadas como bloco homogêneo no processo político, como ator adicional coeso, que não se abre à participação de visões do público, de atores leigos, não especializados na formulação de políticas de ciência e tecnologia.

De acordo com Ruggie et al. (2005), a perspectiva avançada por Ernst Haas incorporou à análise das relações internacionais o processo de racionalização da organização da vida pública, oferecendo uma abordagem segundo a qual as bases da autoridade social seguiriam cada vez mais um modelo burocrático e legal. Esse processo estaria baseado em um entendimento compartilhado existente na própria esfera nacional, que permitiria a definição de entendimentos compartilhados na esfera internacional, fundamentados no conhecimento especializado (RUGGIE et al., 2005).

O cerne da análise burocrática-legal apresenta uma percepção estática e não desconstruída das arenas políticas, associada a um movimento de racionalização do processo político, no qual o conhecimento forneceria bases para uma visão acordada e compartilhada de gestão. Nesta análise, o conhecimento entra como um elemento adicional e importante no processo de aconselhamento político, porém fortemente associado a uma perspectiva tradicional ou, na famosa tipologia proposta por Gibbons et al. (1994), com o "Modo 1 de produção de conhecimento". Tal modo corresponderia ao conhecimento sendo produzido em espaços bem definidos de produção da ciência, por uma classe específica, os cientistas e pesquisadores, e de acordo com normas e orientações próprias. Esse modelo se contrapõe a tendências de produção contemporâneas - ou "Modo 2" -, em que o conhecimento passa a ser produzido com a incorporação de novos atores e conhecimentos não científicos, e marcado pela inter-relação entre distintas esferas e atores.

Visto desta forma, o conhecimento contido nas comunidades epistêmicas não se mostra adequado a uma perspectiva participativa e ampliada da produção do conhecimento e a crescentes demandas por democratização de processos científicos e tecnológicos. Assim, apesar de Haas associar o conceito de comunidades epistêmicas com uma perspectiva construtivista (HAAS, 2001; HAAS, P.M.; HAAS, E. B., 2002), é fundamental compreender que tal perspectiva não dá conta de responder aos avanços da perspectiva construtivista do conhecimento formulada no campo dos estudos sociais da ciência e da tecnologia. Quando se advogam construtivistas, os 
teóricos das comunidades epistêmicas não desconstroem as relações de produção científica, mas a conformação de interesse nos atores analisados - os Estados. ${ }^{2}$

De maneira específica, o conceito não se mostra plenamente adequado a responder às questões que se apresentam nas dinâmicas entre conhecimento e política no cenário internacional contemporâneo, notadamente no que se refere às demandas por maior participação pública nos processos de produção e decisão da ciência. Tais demandas e debates, que convidam a pensar formas de democratizar processos decisórios em ciência e tencologia, têm atuado no sentido de desconstruir categorias de análise tradicionais não problematizadas na concepção das comunidades epistêmicas: atores políticos no processo decisório e a própria distinção entre experts e leigos. Advogam, assim, por espaços políticos que promovam maior consideração de diferentes visões relacionadas à ciência e tecnologia. À medida que ganham amplitude, tais demandas necessitam ser revisadas e repensadas para lidar com novas concepções de conhecimento e novos e velhos problemas da política internacional.

Nas seções seguintes, apresenta-se uma revisão de formatos de ciência aberta, ciência cidadã, que colocam novas questões para a análise da ciência no cenário internacional.

\section{CIÊNCIA, POLÍTICA E PARTICIPAÇÃO: UM DEBATE EM CURSO}

Debates acerca da ampliação da participação na condução da ciência e tecnologia têm ganhado espaço crescente na agenda nacional de diversos países. De maneira geral, as demandas e análises sobre democratização da ciência apontam para o reconhecimento de que a ciência aporta consequências sociais demasiadamente amplas para serem relegadas apenas às esferas científica e política tradicional, geridas de acordo com uma abordagem essencialmente tecnocrática. Novos espaços de participação e consulta sobre rumos científicos e tecnológicos vêm emergindo, e apontam para uma reconfiguração de identidades tradicionais de cidadania e ciência. Esse processo também é impulsionado por uma percepção de limitações das estruturas políticas tradicionais em gerir plenamente, de forma tecnocrática ou "racional", os riscos e danos potenciais de determinados avanços científicos e tecnológicos.

É possível atribuir ao pós-guerra a emergência de teorizações sobre o papel da ciência na política, tendo como marco decisivo o relatório Science, the endless frontier, redigido por Vannevar Bush e direcionado à Presidência dos Estados Unidos, marcando o início de uma nova relação entre Estado e ciência. A visão promovida, encampada pelo governo norte-americano, percebia a ciência como motor do progresso e promotora de benefícios sociais nas mais diversas áreas, em médio e longo prazo (BUSH, 1945). Tal visão permaneceu praticamente inconteste por aproximadamente duas décadas, quando passou a sofrer questionamentos importantes, em grande medida relacionados à ocorrência de inúmeros acidentes

\footnotetext{
${ }^{2}$ É importante ressaltar que o construtivismo nas relações internacionais possui diferentes frentes de análise e vertentes. As comunidades epistêmicas representam apenas uma das correntes dessa vertente, relacionada ao conhecimento. Outras formas de conceituar o conhecimento também se apresentam no campo das relações internacionais, tanto quanto outras perspectivas construtivistas, que não são analisadas neste artigo, mas podem ser encontradas a partir da discussão de Bueger (2014).
} 
nucleares em diversas localidades, além de outros eventos com graves consequências ambientais.

Esses eventos chamaram a atenção pública para as limitações da capacidade de previsão e controle da tecnologia e de danos potenciais de sua aplicação em larga escala. Nesse contexto, emergiram questionamentos e cobranças a respeito dos processos decisórios do desenvolvimento e uso da ciência, da atribuição de responsabilidades, e da capacidade ou não de limitar determinados desenvolvimentos científicos que se mostrem indesejáveis no médio e longo prazo. Tais movimentos apontaram para o caráter de incerteza e imprevisibilidade da ciência e tecnologia, e estabeleceram demandas por espaços de participação pública na determinação de novas trajetórias científicas.

A identificação dessas tendências pelas ciências sociais resultaram em diferentes conceituações que, de modo geral, apontaram para mudanças importantes tanto nos modos de produção da ciência quanto nas relações tecidas entre ciência e sociedade. A clássica obra de Gibbons et al. (1994) propôs uma tipologia que abarcasse dois modos distintos de produção do conhecimento: o modelo tradicional, congregando uma perspectiva linear e isolada da ciência, de acordo com a visão norte-americana do pós-guerra; e um modelo contemporâneo, marcado por mudanças nas práticas de produção de conhecimento nas ciências sociais e naturais, e voltado, prioritariamente para contextos de aplicação. $\mathrm{O}$ "Modo 2" seria marcado pela transdisciplinariedade e heterogeneidade de atores e processos sociais. Uma característica importante a ser destacada consiste no seu controle de qualidade, que tenderia a ser menos endógeno e orientado pela revisão por pares (típico do modelo clássico) e mais reflexivo e direcionado à prestação de contas diante da sociedade. Além disso, a associação entre participantes para sua produção tenderia a ser temporária (GIBBONS et al., 1994).

Para além de uma perspectiva que reconhecesse novas formas de produção de conhecimento, outro tema que recebeu atenção ao atentar para as dinâmicas da ciência nas sociedades modernas foi a sua incorporação nos processos políticodecisórios em democracias. Collingridge e Reeve (1986) identificaram dois pontos críticos fundamentais: o primeiro referente ao fato que, quanto maior o papel de experts no processo decisório, menor é o espaço de participação de cidadãos comuns, sem treinamento ou qualificação específica, representando um desafio em termos democráticos; o segundo, relacionado à prevalência do mito moderno de que a ciência seria capaz de fornecer respostas livres de controvérsia ao processo político, na medida em que estaria pautada em métodos racionais e lógicos de investigação. Esse mito confere um alto grau de autoridade à ciência em processos que necessitam de dados inequívocos ou bases "certas" para a ação política, mas não encontra respaldo na realidade - ponto este que também é levantado por Sarewitz (2004). Assim, houve um crescente reconhecimento no campo das ciências sociais de que o processo científico não leva necessariamente a respostas únicas e que as controvérsias fazem parte do próprio funcionamento da ciência.

Tais desenvolvimentos foram fundamentais para traçar as bases de questionamento acerca do desenvolvimento científico como processo aberto e multidiscplinar, e fundamentaram iniciativas de participação pública na governança da ciência e tecnologia em diversos espaços políticos. Os conceitos de ciência cidadã, cidadãos cientistas e diferentes tipos de expertise compuseram parte dessa nova concepção de ciência, ampliada em seus canais de produção e abrindo espaço para imaginar formas de engajamento e democratização nas decisões informadas por conhecimento. 
De um lado, destacam-se as iniciativas de conformação de ciência cidadã ou ciência de colaboração massiva (crowd science), que consistem em formas de organização da pesquisa em projetos colaborativos. Tais projetos se caracterizam pela participação aberta a uma ampla base de contribuidores, sem distinção prévia entre experts e leigos; e pela capacidade de receber inputs intermediários, como dados ou algoritmos para a resolução de problemas, que são disponibilizados abertamente aos que participam da rede (FRANZONI; SAUERMANN, 2014). Assim, no formato de ciência aberta, há um crescente envolvimento de novos atores, não apenas cientistas ou especialistas, que participam com inputs e esforços, a partir de uma base de contribuidores diversa, o que permite expandir o rol de problemas a serem abordados, a um baixo custo e crescente velocidade de resolução (FRANZONI; SAUERMANN, 2014; WIGGINS; CROWSTON, 2015).

De outro lado, identifica-se uma crescente literatura sobre o engajamento público na ciência, bastante associada ao desenvolvimento de espaços alternativos de participação nos contextos europeu e norte-americano. Esses desenvolvimentos se associam, de acordo com Sykes e Macnaghten (2013), a algumas dinâmicas centrais que ocorreram sucessivamente e abriram espaço a diferentes concepções nos formatos de relacionar ciência e política. Assim, na década de 1960, foram notáveis os protestos contra projetos e visões tecnológicas, especialmente nos movimentos ambientais e antinucleares. A partir de então, houve uma crescente exigência de que governos e parlamentos detivessem conhecimento robusto sobre impactos de novos desenvolvimentos científicos e tecnológicos para melhor antecipar suas consequências sociais, o que motivou, na década de 1970, o estabelecimento de estruturas inseridas no processo legislativo e decisório tradicional de vários países, orientadas a empreender a avaliação de tecnologias (technology assessment organizations). Tais organismos foram inseridos em parlamentos de países europeus e norte-americanos, com o objetivo de fornecer conhecimento e informações consideradas precisas e confiáveis, para embasar o processo de tomada de decisões.

Em seguida, destacaram-se as demandas pela extensão de espaços de participação cidadã, incluindo grupos organizados da sociedade civil; e, finalmente, as demandas da comunidade científica, de maneira geral, para aprimorar a "compreensão pública da ciência" (public understanding of science), de acordo com uma visão de que os conflitos e tensões entre público e cientistas seriam derivados da falta de compreensão científica pelo público leigo (SYKES; MACNAGHTEN, 2013).

As propostas para medir e ampliar a compreensão pública da ciência e o estabelecimento de organizações especializadas no âmbito governamental para informar sobre potenciais riscos e melhores alternativas de gestão aos governos foram os principais instrumentos de ampliação participativa adotados em um primeiro momento por diversos países. Não obstante, esses formatos sofreram críticas ou se mostraram limitados na proposição de diminuir as tensões entre ciência e sociedade. Acerca da compreensão pública da ciência, Jasanoff (2005) apontou para as limitações dessa perspectiva em problematizar o status científico como forma de conhecimento livre de falhas: as iniciativas de promoção da compreensão pública científica entre cidadãos foram geralmente marcadas por uma visão não problemática da ciência, entendida como universal e homogênea, conduzindo sempre um caminho progressivo e livre de controvérsias. De outro modo, a grande maioria de agências governamentais foi extinta ou substituída, à medida que não se adequavam ao processo político em marcha nos seus países de origem.

Ainda assim, tais movimentos marcaram uma continuidade nos processos que promoviam a necessidade de ouvir e considerar o público em torno de decisões 
científicas ou tecnológicas, ${ }^{3}$ abrindo espaço, em países europeus e nos Estados Unidos, a variados formatos recentes de engajamento público em C\&T. Exercícios de consulta pública mostraram-se mais frequentes em países escandinavos, como é o caso da Dinamarca e da Suécia, de acordo com uma cultura política presente nesses países marcada por debates e engajamento no nível local. O modelo adotado nesses contextos é conhecido como "cúpulas cidadãs" (citizen summits), e se configura como arenas de debate público, promovidas em nível local ou regional, orientadas à consulta pública para informar decisões políticas (IRWIN, 2015).

Iniciativas de âmbito nacional também se destacaram, ao incorporar à política nacional visões e percepções públicas: é o caso da consulta popular sobre organismos geneticamente modificados na Inglaterra - "GM Nation?" e do "fórum de transparência" sobre riscos de telefones celulares organizado na Suécia (LEZAUN; SONERYD, 2007). Além dessas propostas, a literatura também identifica a realização de workshops para recolher visões de diferentes grupos, incluindo o público, acerca de desafios contemporâneos, entre outros modelos (HORLICK-JONES et al., 2007; IRWIN, 2006; SYKES; MACNAGHTEN, 2013).

Os variados exemplos de engajamento público foram explorados por uma vasta literatura ${ }^{4}$ e as análises sobre tais experimentos apontaram para alguns pontos centrais. Irwin (2006), Jasanoff (2003) e Wynne (1992) reconhecem que, para além da implementação de formatos e iniciativas de participação e compreensão pública da ciência, é necessário promover uma mudança cultural nos padrões de decisão pública envolvendo C\&T. Esses autores apontam que o estabelecimento de canais participativos, por si só, não é suficiente para uma transformação efetiva das formas tradicionais e arraigadas de tomada de decisão em C\&T, e não tem promovido uma real incorporação da percepção pública no processo decisório. Jasanoff insiste na necessidade de reformular as bases de governança da ciência e tecnologia, por meio do que a autora denomina de "tecnologias de humildade": modos de governança em C\&T que reconheçam e avaliem o conteúdo desconhecido, incerto, muitas vezes ambíguo e incontrolável dos sistemas tecnológicos. Tais tecnologias demandam novas formas de engajamento entre especialistas, políticos e o público, e consistem no reconhecimento de que as formas como questões e objetos em análise são considerados (framing) é fundamental para o resultado final do debate; na consideração da vulnerabilidade desigual dos grupos analisados, indo além de análises puramente estatísticas de risco; na distribuição efetiva do processo decisório em diferentes esferas, tirando do "comitê de especialistas" a palavra final na consideração tecnológica; e a capacidade de aprender com episódios passados, incorporando o desconhecido nas decisões. Apenas empreendendo essas mudanças, haveria uma verdadeira transformação necessária na postura e nos preceitos-base presentes nos processos decisórios e deliberativos em C\&T (JASANOFF, 2003).

\footnotetext{
${ }^{3}$ O episódio da "doença da vaca louca", no Reino Unido, representou um marco no reconhecimento do público nas decisões públicas envolvendo riscos e incertezas.

${ }^{4}$ Conferir, por exemplo, Hagendijk e Irwin (2006); Horst et al., (2007); Mejlgaard et al. (2012); Horst, (2008); Horlick-Jones et al. (2007).
} 


\section{TIPOLOGIAS DE GOVERNANÇA CIENTÍFICA: DIFERENTES FORMATOS DE PARTICIPAÇÃO}

O projeto Stage (Science, Technology and Governance in Europe) ${ }^{5}$ identificou diferentes tipos de governança em ciência e tecnologia existentes em oito países europeus, e estabeleceu a seguinte tipologia: 1) governança discricionária, marcada por políticas de C\&T sem interação explícita com o público, em que a governança é considerada uma questão de governo a ser levada a cabo por representantes eleitos; 2) governança corporativista, que envolve um reconhecimento formal das diferenças de interesses, como insumos das negociações - nesse modelo, a negociação ocorre em ambiente altamente regulado e admite a presença e participação de stakeholders e participação pública ampliada, incluindo vozes, perspectivas e interesses conflitantes nas negociações com contribuição de diferentes fontes; 3) governança educativa, que segue uma perspectiva de que o público não tem acesso ao conhecimento, e que cabe ao governo, por meio de agências nacionais, promover a educação científica; 4) governança de mercado, em que ciência e tecnologia são vistas como reguladas por demanda e oferta, e o público participa como consumidor e tendência à crescente liberalização e desregulamentação das atividades científicas; 5) governança agonística, que ocorre em contextos de confrontação e adversidade, podendo resultar em formas discricionárias e corporativistas de tomada de decisão exemplificada pelos casos de armazenamento de lixo nuclear e da oposição a alimentos geneticamente modificados na Inglaterra; 6) governança deliberativa, que reside na presunção de que debate aberto e engajamento possam criar um fundamento satisfatório para a tomada de decisões. No modelo de governança deliberativa, o público não é percebido como consumidor da ciência, mas como "cidadãos científicos", estimulados a participar ativamente da condução da política de C\&T, como exemplificado no formato das conferências de consenso. O relatório reconhece que alguns tipos de governança podem coexistir em um mesmo país. Assim, há casos em que se identifica uma governança discricionária e educativa nas iniciativas colocadas em prática por um mesmo país (HAGENDIJK; IRWIN, 2006; HORST et al., 2007).

$\mathrm{Na}$ tipologia do projeto Stage, é possível perceber a coexistência de diferentes percepções da participação pública: em alguns modelos, o público é relegado à condição de absorvedor de decisões tomadas pelas instâncias responsáveis políticos e experts; em outros, a participação cidadã é percebida como insumo do processo político. Essa dissonância no tratamento do público pelas iniciativas de governança existentes consiste em uma preocupação central das análises de participação pública em $C \& T$ e apresentam desafios às análises e experimentos de engajamento. De modo geral, um desafio que se apresenta consiste em promover um espaço efetivo para ouvir e recolher visões e impressões do público e, posteriormente, permitir uma inserção efetiva desses insumos no processo decisório e nas políticas decorrentes de ciência e tecnologia.

Os diferentes formatos identificados na experiência europeia permitem pensar um ponto fundamental no diálogo que se propõe entre uma perspectiva de ciência aberta e cidadã e sua implementação para além das fronteiras nacionais. Se a noção de comunidades epistêmicas, da forma como é empreendida nas análises de relações

\footnotetext{
5 Projeto implementado pela Comissão Europeia entre 2001 e 2005, que analisou iniciativas de governança da ciência e tecnologia em oito países: Dinamarca, Finlândia, Grécia, Holanda, Noruega, Portugal, Reino Unido e Suécia.
} 
internacionais, não se mostra adequada a tais configurações de participação científica, como pensar tais desenvolvimentos em uma arena transnacional? Diante da multiplicidade de formatos possíveis para gerir a C\&T, quais reconhecem e promovem, efetivamente, uma crescente consideração dos anseios públicos nos processos decisórios nacionais e internacionais?

Irwin (2015) levanta esses debates e aponta para a necessidade de estender a compreensão da governança científica para além dos governos nacionais, reconhecendo e atuando em redes e associações mais amplas por meio das quais os processos decisórios e de implementação da $C \& T$ se estabelecem. O contexto da globalização aparece como desafio essencial para a obtenção de ganhos efetivos nas práticas de democratização científica e tecnológica.

Um caminho traçado pelo autor consistiria em identificar os múltiplos centros de governança, que perpassam governos e parlamentos, assembleias regionais, organismos internacionais, organizações industriais, assessores científicos e especialistas, além de consumidores e cidadãos. Uma vez reconhecidos tais centros de governança, a proposta de democratização também requereria identificar quem estaria pronto a absorver as deliberações públicas. O desafio, não obstante, deriva da própria mudança na natureza da governança contemporânea, em que o engajamento público é apresentado como um problema de ordem prática diante da crescente descentralização decisória das redes globais (IRWIN, 2015). Nessa perspectiva, os experimentos de engajamento público aparecem como principal estratégia de ação, em processos de tentativa e erro, e direcionados à constante adaptação. As relações de poder são reconhecidas como importante fator na abertura ou não das redes e processos tradicionais a formatos alternativos de engajamento.

\section{PROPOSTAS DE AÇÃO COLOCADAS EM PRÁTICA}

A fim de dar conta de uma incorporação significativa das perspectivas e participação dos cidadãos nos processos decisórios, Callon, Lascoumes e Barthe (2010) propuseram deixar de lado as distinções tradicionais entre especialistas e leigos, em fóruns marcados pela multiplicidade de atores, ideias e perspectivas. Os "fóruns híbridos" envolvem diferentes grupos sociais e são marcados por uma pluralidade de pontos de vista, uma abertura de perspectivas, incertezas e compreensões. Esse processo é reivindicado como uma opção melhor do que "fechar" os formatos de engajamento público, representados por tentativas de construção de consenso. $O$ reconhecimento de múltiplas visões seria um ganho na contabilidade democrática do engajamento público. Esses laboratórios híbridos na condução do desenvolvimento científico deveriam, na visão dos autores, ser complementados por experimentações constantes empreendidas no mundo real, em diferentes fases do desenvolvimento científico - sejam elas antecedentes ou concomitantes à inovação e à sua implementação na sociedade.

Mais recentemente, tem ganhado impulso no contexto acadêmico e político o conceito de "inovação responsável", que retoma elementos apontados pelas "tecnologias da humildade" de Jasanoff. O conceito é definido por Stilgoe, Owen e Macnaghten (2013) como um formato de "cuidar do futuro por meio de controle e governança [stewardship] coletivo da ciência e inovação no presente" (STILGOE; OWEN; MACNAGHTEN, 2013, p. 1.570). São indicadas quatro dimensões centrais da inovação responsável: a antecipação de potenciais resultados, benéficos ou não; a reflexividade de atores e instituições, ou seja, sua capacidade de crítica autorreferenciada, que reconheça as próprias práticas e os limites do conhecimento 
no presente acerca de consequências futuras; a inclusão de diferentes atores sociais no processo inovativo; e responsividade (responsiveness), referindo à capacidade de reagir e responder aos novos desenvolvimentos, à medida que apresentem riscos ou trilhem trajetórias não desejadas - em suma, ser capaz de apresentar mudanças de trajetória após a inovação ser lançada (STILGOE; OWEN; MACNAGHTEN, 2013).

Essas dimensões se relacionam à percepção de que a inovação tecnológica é levada adiante por imaginários acerca do desenvolvimento compartilhados por participantes centrais do processo de inovação. As demandas e exercícios de participação pública buscam justamente: inserir o público no rol de participantes capazes de influir nos processos inovativos e participar das discussões antecipatórias de desenvolvimentos tecnológicos, direcionando as trajetórias de pesquisa e desenvolvimento (antecipação); permitir um constante pensamento crítico acerca das trajetórias institucionais percorridas pelo desenvolvimento científico e tecnológico (reflexividade); e apontar processos, instituições e atores responsáveis, uma vez que riscos tecnológicos sejam identificados, com o intuito de permitir uma reação eficaz e rápida aos desenvolvimentos que aportem consequências indesejáveis (responsabilização).

Tanto a proposição de foros híbridos como de inovação responsável apresentam critérios para sua implementação, e têm sido adotadas em iniciativas recentes de governança de C\&T, como é o caso do Projeto Horizon 2020, ${ }^{6}$ implementado pela Comissão Europeia (COMISSÃO EUROPEIA, 2016). Há, ainda, o reconhecimento da importância na promoção de uma forma de ciência mais aberta por parte da OCDE (OCDE, 2015). Dessa forma, percebe-se a incorporação de avanços teóricos sobre democratização e governança da C\&T por parte de instituições públicas, denotando um reconhecimento dessas demandas pelos meios institucionais mais amplos de governança científica, embora restrito a alguns contextos específicos.

\section{CONCLUSÃO}

Os debates envolvendo a ampliação da participação pública na ciência remetem a formas e experimentos para lidar com uma ciência cada vez mais presente e influente no cotidiano social, que buscam se adequar ao caráter ambíguo e incerto de futuros desenvolvimentos científicos e, ao mesmo tempo, garantir uma democratização de seus processos decisórios diante das incertezas. Um elemento fundamental desse debate consiste no reconhecimento da vulnerabilidade diferenciada de indivíduos e populações em relação a riscos e desenvolvimentos tecnológicos, e aponta para a necessidade de democratização de decisões científicas e tecnológicas como conformação de um espaço político democrático e mais equânime na distribuição de riscos. Nesse sentido, o aspecto da incorporação de diferentes grupos e visões sociais adquire relevância central nas demandas por uma governança mais participativa e democrática, pautada em uma nova percepção do fazer científico.

Apesar do avanço das discussões e experimentos em alguns contextos locais e regionais, o tema da democratização da C\&T permanece pouco explorado em discussões da ciência e tecnologia em âmbito internacional ou global. Há, de maneira

\footnotetext{
${ }^{6}$ O Horizon 2020 é o maior programa de investigação e inovação da União Europeia, com cerca de 80 bilhões de euros de financiamento disponível ao longo de sete anos (2014-2020). O programa se direciona à pesquisa, ao desenvolvimento e às inovações promovidas por instituições do continente, e também busca atrair investimentos do setor privado (HORIZON 2020, 2017).
} 
geral, nas teorizações das relações internacionais, a predominância de uma percepção essencialmente exógena da ciência, associada ao modelo tradicional, em que ela é percebida como insumo estratégico dos países na condução de sua política externa - seja em sua busca por ampliação de seu poder relativo em relação a outros países ou no estabelecimento de cooperação internacional. Este artigo se limitou a debater o conceito de comunidades epistêmicas e ilustrar como seu uso pelas relações internacionais, embora revele um desejo de investigar o papel da ciência na política internacional, não abre espaço para novas considerações do conhecimento contemporâneo, enquanto empreendimento social multidisciplinar; tampouco incorpora o aspecto da democratização da C\&T abundantemente explorados pelos estudos sociais da C\&T.

A revisão do conceito de comunidades epistêmicas buscou revelar algumas dissonâncias e espaços para a consideração do conhecimento na análise internacional, que levasse em consideração temas correntes levantados pela sociologia contemporânea, tais como a consideração de riscos, o aspecto da incerteza e ambiguidade em relação ao futuro da C\&T, a distribuição desigual e vulnerabilidade de indivíduos e grupos, que alimentam demandas por maior participação e democratização das esferas de governança. Nesse sentido, ao identificar a predominância de uma perspectiva clássica e tradicional da ciência no conceito de comunidades epistêmicas, chama-se a atenção para a utilidade de uma perspectiva que reconheça os desenvolvimentos nas relações entre ciência e sociedade, mais adequada à realidade internacional contemporânea e à centralidade da ciência no que se refere a novos arranjos e demandas sociais.

Assim, chama-se a atenção para a complexidade das relações entre o público e os formatos mais recentes de produção de conhecimento como um elemento que deve ser mais atentamente percebido em suas dinâmicas internacionais, de modo a revelar faces muitas vezes subjacentes dos processos científicos nas arenas internacionais. A literatura sobre ciência cidadã mostra que a ampliação dos espaços de produção de conhecimento já é uma realidade; os formatos de gestão desse conhecimento cúpulas cidadãs e fóruns híbridos, em grande parte experimentais - buscam responder a essa tendência de abertura em direção oposta: se ela ainda se mostra essencialmente unilateral, restrita à produção, é preciso ampliar seus espaços de decisão e gestão. Tais questões são fundamentais em um contexto internacional crescentemente afetado pela ciência, e não podem escapar à sua consideração.

Artigo recebido em 31/01/2017 e aprovado em 23/05/2017.

\section{REFERÊNCIAS}

BUEGER, C. From expert communities to epistemic arrangements: situating expertise in international relations. In: MAYER, Maximilian; CARPES, Mariana; KNOBLICH, Ruth (Ed.). The global politics of science and technology. [S.I.]: Springer, 2014. v. 1, p. 39-54.

BUSH, Vannevar. Science, the endless frontier.Washington, DC:_United States Government Printing Office, 1945.

CALLON, M.; LASCOUMES, P.; BARTHE, Y. Acting in an uncertain world. Boston, MA: MIT Press, 2010.

COLLINGRIDGE, D.; REEVE, C. Science speaks to power: the role of experts in policy making. New York: St. Martin's Press, 1986. 
COMISSÃO EUROPEIA. Open innovation, open science, open to the world: a vision for Europe. Luxembourg: Publications Office of the European Union, 2016.

FRANZONI, C.; SAUERMANN, H. Crowd science: the organization of scientific research in open collaborative projects. Research Policy, v. 43, p. 1-20, 2014.

GIBBONS, M. et al. The new production of knowledge: the dynamics of science and research in contemporary societies. London: Sage, 1994.

HAAS, E. B. Beyond the nation state: functionalism and international organization. Colchester, UK: ECPR Press, 2008.

HAAS, P. M. Policy Knowledge : epistemic communities. In: SMELSER, Neil J. ; BALTES, Paul B. (Ed.). International encyclopedia of the social \& behavioral sciences. [S. I]:Elsevier, 2001. p. 11.578-11.586.

HAAS, P. M.; HAAS, E. B. Pragmatic constructivism and the study of international institutions. Millennium-Journal of International Studies, v. 31, n. 3, p. 573-601, 2002.

HAGENDIJK, R. O. B.; IRWIN, A. Public deliberation and governance: engaging with science and technology in contemporary europe. Minerva, v. 44, n.2, p. 167-184, Jun. 2006.

HORIZON 2020. What is Horizon 2020? Disponível em: <https://ec.europa.eu/programmes/horizon2020/en/what-horizon-2020>. Acesso em: 30 jan. 2017.

HORLICK-JONES, T, J. et al. The GM Debate. [S.I.]: Routledge, 2007.

HORST, M. et al. European scientific governance in a global context: resonances , implications and reflections. IDS Bulletin, v. 38, n. 5, p. 6-20, 2007.

IRWIN, A. On the local constitution of global futures. Science and democratic engagement in a decentred world. Nordic Journal of Science and Technology Studies, v. 3, n. 2, 2015.

. The politics of talk: coming to terms with the "new"scientific governance. Social Studies of Science, v. 36, n. 2, p. 299-320, 2006.

JASANOFF, S. Technologies of humility. Nature, v. 450, n. 7.166, p. 33, 2003.

KRASNER, S. D. International regimes. Ithaca, NY: Cornell University Press, 1983.

LEZAUN, J.; SONERYD, L. Consulting citizens: technologies of elicitation and the mobility of publics. Public Understanding of Science, v. 16, n. 3, p. 279-297, 1 jul. 2007.

LITFIN, K. Ozone discourses: science and politics in global environmental cooperation. New York: Columbia University Press, 1994.

MEJLGAARD, N. et al. Monitoring policy and research activities on science in society in Europe (MASIS). Final synthesis report. Luxemburgo: European Comission, 2012. Disponível em:<https://ec.europa.eu/research/sciencesociety/document_library/pdf_06/monitoring-policy-research-activities-on-

sis_en.pdf $>$.

MITRANYI, D. A working peace system. Londres: Royal Institute of International Affairs, 1943.

OCDE. Making open science a reality. OECD Science, Technology and Industry Policy Papers, n. 25, p. 1-108, 2015. 
RUGGIE, Gerard J. et al. Transformations in world politics: the intellectual contributions of Ernst B. Haas. Annual Review of Political Science, v. 8, p. 271-296, 2005.

SAREWITZ, D. How science makes environmental controversies worse. Environmental Science \& Policy, v. 7, n. 5, p. 385-403, 2004.

STILGOE, J.; OWEN, R.; MACNAGHTEN, P. Developing a framework for responsible innovation. Research Policy, v. 42, n. 9, 2013.

STRANGE, S. States and markets. Londres: Bloomsbury Publishing, 2015.

SYKES, K.; MACNAGHTEN, P. Responsible innovation: opening up dialogue and Debate. In: OWEN, R.; HEINTZ, M.; BESSANT, J. (Ed.). Responsible innovation. London: John Wiley, 2013. p. 85-107.

WIGGINS, A.; CROWSTON, K. Surveying the citizen science landscape. First Monday, v. 26, n. 1, p. 1-14, Jan. 2015.

WYNNE, B. Misunderstood misunderstanding: social identities and public uptake of science. Public Understanding of Science, v.1, n.3, p. 281-304, 1992. 